\title{
The Characteristics and Boundary of Social Media Language Communication Mode under the Pragmatic Boundary in the New Period
}

\author{
Chen Zepeng \\ Department of Linguistics and Translation, City University of Hong Kong, Hongkong, China, 999077 \\ Corresponding Author email: chenzepeng16@126.com
}

Keywords: Social media; language; communication.

\begin{abstract}
The intense public discussion on privacy reflects the complexity and diversity of privacy issues in social change. As a new communication tool, social media leads to the reshaping of communication behavior and social relations under the new information mode. Especially the social media network which has a profound impact on people's lives, the special mode of communication produces special critical language, and the new critical language reacts to the media. This paper analyzes the communication voice, the way of expression, the use of image language and the discourse innovation brought by social media, and proposes to change the communication voice and narrative habits, from speaking Mandarin to telling stories. It has a different operational logic from traditional media. Social media comprehensively constructs the subject and its social relationships, and generates the mutual structure of the relationship. Art criticism incorporates the characteristics of the media itself in the process of social network environment, and generates artistic criticism with specific context and meaning. Multi-lingual closeness, from Chinese thinking to foreign language thinking in the way of expression, attach importance to image language and packaging. It also analyzes how to grasp the innovation of discourse brought by social media and integrate the Chinese and foreign discourse system from three levels. This deconstructs the traditional privacy with the right-oriented control concept. The new privacy cognition is based on the perspective of relationship, and the mutual rules with social attributes are derived. At the same time, privacy protection requires the subject to dynamically manage the boundaries in the relationship-differentiated thinking, thereby maintaining the orderliness of social media reciprocity.
\end{abstract}

\section{Introduction}

According to the China Internet Network Information Center, by December 2015, China had 688 million Internet users, 50.3\% of whom had access to the Internet [1]. From oral transmission to paper media, from paper media to television media, from television media to network media, every media update must be accompanied by a major change in its attachments [2]. Among them, social media presents the trend of rapid growth of users, diversification of structure and regional diffusion, which has gradually become the mainstream media form of society [3]. Different from traditional media, social media brings a new form of communication and information, constantly reshaping the subject construction and interpersonal interactions that are generated by them, and changing the existing relationship between the subject and society [4]. Different from the art criticism of the past era, the current social development is in the peak of the network age, and the discipline system involved in art is as large as the data. At the same time of changing and promoting social interaction, the privacy issues brought about are brought to the forefront [5].

\section{The nature and characteristics of using social media for language communication}

Some language training entities or online foreign language learning websites also register micro-blog, micro-mail public accounts, such as VOA, Crazy English, New Oriental, EF education, Weber International English, Wall Street English, etc. These language training institutions use social 
media such as micro-blog and micro-letter to publish knowledge and news about English learning. Whether it is personality protection or emphasis on freedom, the original intention is still to confine privacy issues to the private sphere rather than the public sphere. In Western important privacy theory, Westin holds that privacy is the idea that individuals, groups or organizations themselves decide when, how and to what extent their information is transmitted to others. This is when social media becomes a commercial medium, and through marketing, language training entities can attract potential customers, i.e. trainees, to participate in language training. Facing the changes brought by the mass media, it guarantees individuals the ability to control and disseminate relevant information in their interactions. The right to maintain absolute solitude in mutual relations constitutes the core connotation of privacy. It reflects that they are not satisfied with the existing known expressions, pursuing new and new expressions of individual expressions, new development trends, whether Chinese or English. The statistics of the direct quotation and the use of the quotation in the selected text are shown in Table 1.

Table 1 Statistics on the use of direct quotations and ten-speakers in selected texts

\begin{tabular}{|c|c|c|c|c|c|c|c|c|c|}
\hline & \multicolumn{3}{|c|}{ Japanese official } & \multicolumn{3}{|c|}{$\begin{array}{l}\text { Official bodies and media } \\
\text { in other countries }\end{array}$} & \multicolumn{3}{|c|}{ Other } \\
\hline & $\begin{array}{l}\text { Direct } \\
\text { quotations }\end{array}$ & $\begin{array}{c}\text { Indirec } \\
\text { t } \\
\text { speech }\end{array}$ & $\begin{array}{l}\text { Mixed } \\
\text { speech }\end{array}$ & $\begin{array}{l}\text { Direct } \\
\text { quotations }\end{array}$ & $\begin{array}{c}\text { Indirec } \\
\text { t } \\
\text { speech }\end{array}$ & $\begin{array}{l}\text { Mixed } \\
\text { speech }\end{array}$ & $\begin{array}{c}\text { Direct } \\
\text { quotations }\end{array}$ & $\begin{array}{c}\text { Indirec } \\
\text { t } \\
\text { speech }\end{array}$ & $\begin{array}{l}\text { Mixed } \\
\text { speech }\end{array}$ \\
\hline $\begin{array}{l}\text { China } \\
\text { Daily }\end{array}$ & 1 & 5 & 2 & 1 & 1 & 2 & 5 & 2 & 3 \\
\hline CNN & 4 & 6 & 2 & 8 & 2 & 0 & 3 & 0 & 1 \\
\hline
\end{tabular}

In this paper, we use the method of Chinese character tagging to establish the CRF model, and use the method of feature annotation as shown in Table 2.

Table 2 Chinese character tagging feature

\begin{tabular}{ccc}
\hline Number & Features & Feature description \\
\hline 1 & $\mathrm{C}_{0}$ & Current character \\
2 & $\mathrm{C}_{1}$ & The current character is back to a character \\
3 & $\mathrm{C}_{2}$ & The current character is two characters backward \\
4 & $\mathrm{C}_{-1}$ & The current character is forward one character \\
5 & $\mathrm{C}_{-2}$ & The current character is forward two characters \\
\hline
\end{tabular}

In this experiment, after repeated verification, the final selected parameter $C$ has a value of 2 . The experimental results are shown in Table 3.

Table 3 Test result

\begin{tabular}{cccc}
\hline & Correct rate (\%) & Recall (\%) & F value \\
\hline $\begin{array}{c}\text { Tagging CRF } \\
\text { model without } \\
\text { word of speech } \\
\begin{array}{c}\text { Tagging CRF } \\
\text { model with part of } \\
\text { speech }\end{array}\end{array}$ & 89.84 & 95.61 & 0.9417 \\
\hline
\end{tabular}

Social media language communication and learning involve rich languages. Some languages are difficult to find either in school or in society. Rare languages such as Finnish and Swahili can be found in social media accounts, as well as in Esperanto, an artificial language. The dissemination effect of social media on art criticism is more than that. Compared with the linear communication, circular communication and systematic communication, the dissemination of social media has made more breakthroughs. In China's law, social development has prompted the emergence of privacy 
violations, the right to privacy has become a well-known concept and proposition. However, there is a lack of clear provisions and judicial interpretations in the legal system, and privacy rights are somewhat unfamiliar. With these accounts, you can get many free resources in very common language, which is very practical. It can be seen that individuals using social media to learn foreign languages can meet the needs of different language learners and enthusiasts at different levels and in different fields. From this perspective, social media accounts in non-universal languages, especially the less commonly used languages, to some extent compensate for the lack of formal school language settings.

\section{The linguistic characteristics of art criticism in social media environment}

The choice of media in art criticism is also the choice of the purpose of art criticism. No matter what the purpose of art criticism is, it is impossible to get rid of the limitation of critical language. Self-disclosure is a prerequisite for the formation of various social contacts and relationships, and social media serves as a platform for information sharing, relationship transformation and social interaction. It greatly meets people's mutual need for self-disclosure, based on self-expression and emotional sharing. To achieve social interaction, participation and other purposes, and then to the construction of social capital, communication and identity. If language teaching outside the classroom is collectively referred to as non-mainstream language teaching, then non-mainstream language teaching has long appeared in human society. In addition to the still existing but somewhat diversified distance education and correspondence studies, new teaching and learning methods and means are emerging, such as open classrooms, community learning, and online education.

By summarizing all the sections manually, statistics are carried out according to five subject categories: financial finance, campus education, literature and art, emotional communication, and news talks. The statistics that can not be included are counted in other subject areas, and the results as shown in Table 4 are obtained.

Table 4 Corpus topic category statistics

\begin{tabular}{cccccc}
\hline $\begin{array}{c}\text { Subject } \\
\text { category }\end{array}$ & $\begin{array}{c}\text { Financial } \\
\text { finance }\end{array}$ & $\begin{array}{c}\text { Campus } \\
\text { education }\end{array}$ & $\begin{array}{c}\text { Literature } \\
\text { and Art }\end{array}$ & $\begin{array}{c}\text { Share } \\
\text { feelings }\end{array}$ & News talk \\
\hline $\begin{array}{c}\text { Number of } \\
\text { topics }\end{array}$ & 6513 & 1265 & 5123 & 15642 & 35164 \\
\hline
\end{tabular}

From the overall cross-validation statistics, it is true. The results are shown in Table 5.

Table 5 CRF test results for word segmentation and event elements

\begin{tabular}{cccc}
\hline Experiment number & Correct rate (\%) & Recall (\%) & F value \\
\hline 1 & 51.51 & 32.54 & 0.1849 \\
2 & 63.18 & 42.48 & 0.1144 \\
3 & 62.54 & 39.89 & 0.1574 \\
4 & 68.16 & 40.11 & 0.1951 \\
5 & 59.18 & 32.18 & 0.1781 \\
\hline
\end{tabular}

Using the same method as the Chinese word segmentation, we do the same training and testing of the linguistic features of the named entity. The results are shown in Table 6.

Table 6 CRF test results for named entity recognition and event elements

\begin{tabular}{cccc}
\hline Experiment number & Correct rate (\%) & Recall (\%) & F value \\
\hline 1 & 64.15 & 15.84 & 0.0159 \\
2 & 56.49 & 12.94 & 0.0132 \\
3 & 38.18 & 11.18 & 0.0544 \\
4 & 54.19 & 14.15 & 0.0184 \\
5 & 45.94 & 10.69 & 0.0151 \\
\hline
\end{tabular}

The interconnection structure of social media makes the rules of interaction chaotic in the process of situation replacement caused by the continuous diffusion of relationships. In the context of oral 
and written media, communication follows the appropriateness of norms and the principle of transmission. The interaction process is based on the common situation and forms the rules of mutual compliance. As for the language of art criticism, it is also facing the trend of language transparency. The characteristics of text language are weakening. Meanwhile, the media language is gradually rising. The change of the media is irreversible, but it will lead to other forms of ideology. The expansion of textual language in social media and the expansion of art in the network are in the opposite direction. The signifiers and artistic extensions of artistic language have never stopped. The art criticism based on words gradually loses the signifying function of words. Criticism seems to be "single-shaped" in social media. Therefore, in the face of the rich and pluralistic language of contemporary art, critics, in addition to understanding contemporary art theory, must also strengthen the function of criticism.

\section{Conclusion}

Privacy problems and practical experience caused by social media prompt people to rethink the concept of privacy and reconstruct its operational norms. Different from the Western emphasis on the absoluteness of individual value and freedom under the framework of natural rights, we should consider the social significance of privacy protection in the context of reality. Art criticism in the media environment involves disciplines such as criticism, communication, linguistics, or iconography. No subject can be the dominant factor in the art world full of images, capital and new media, nor can it be ignored in academic research. As a concrete manifestation of the construction of social norms, privacy should be regarded as social practice, and its role should be placed in the specific social environment to analyze the results and effects of its production. The disciplines involved in this paper, especially in communication, require a large amount of materials and data to be obtained in a long-term and professional collection, and the research methods are quite different from the art theory. But this does not mean that we should stop. "The new media is often in the parameters and framework of the old media." There is still room and time to understand the impact of the development of media and art criticism.

\section{References}

[1] Nulty P, Theocharis Y, Popa S A, et al. Social media and political communication in the 2014 elections to the European Parliament $\underset{\sim}{\sim}[\mathrm{J}]$. Electoral Studies, 2016, 44:429-444.

[2] Dondurucu Z B, Ulucay A P. The Evaluation of Political Communication Strategies in Social Media According To Content Differences [J]. Journal of Virology, 2016, 82(1):40-8.

[3] Tutku Baföz. Pre-service EFL Teachers Attitudes towards Language Learning through Social Media [J]. Procedia - Social and Behavioral Sciences, 2016, 232:430-438.

[4] Stier S, Bleier A, Lietz H, et al. Election Campaigning on Social Media: Politicians, Audiences, and the Mediation of Political Communication on Facebook and Twitter [J]. Political Communication, 2018, 35(1):50-74.

[5] Georgakopoulou A. 'Whose context collapse?' Ethical clashes in the study of language and social media in context [J]. Applied Linguistics Review, 2016, 8(2-3):169-189. 